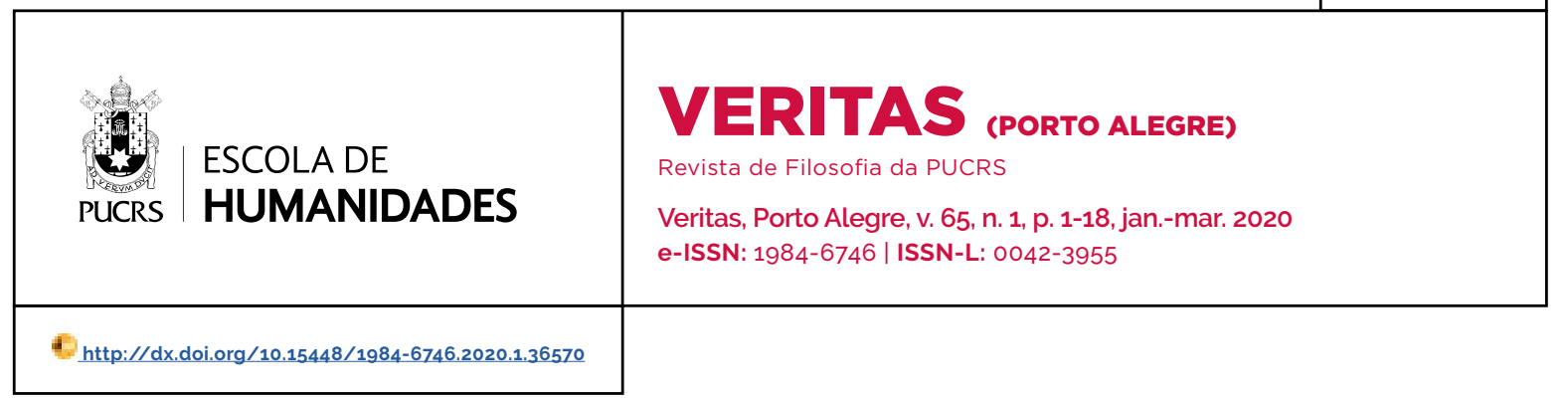

SEÇÃO: VARIA

\title{
A questão fundamental da crítica de Tugendhat a Heidegger: falsidade, descerramento e a transição semântica de 'verdade'1
}

\author{
The Fundamental Issue in Tugendhat's Critique of Heidegger: Falsehood, Disclosure, \\ and the Semantic Transition of 'Truth' \\ La cuestión fundamental en la critica de Tugendhat a Heidegger: falsidad, apertura y la \\ transición semántica de la 'verdad'
}

\section{Paulo Mendes Taddei ${ }^{2}$ orcid.org/0000-0001-5895-7604 paulo.taddei@gmail.com}

Recebido em: 1 dez. 2019. Aprovado em: 5 jan. 2020. Publicado em: 12 mai. 2020.

\section{(c) (i)}

Artigo está licenciado sob forma de uma licença Creative Commons Atribuição 4.0 Internacional.
Resumo: Reconstroem-se, neste artigo, as objeções de Daniel Dahlstrom (2001) e Rufus Duits (2007) à critica de Tugendhat (1970) à tese heideggeriana de que o conceito primordial de verdade consiste na noção de desvelamento (Unverborgenheit). De diferentes modos, ambos os autores mantêm que Heidegger, ao contrário das acusações de Tugendhat, seria capaz de dar conta da falsidade. Grosso modo, enquanto Dahlstrom propõe que Tugendhat não apreciou o caráter transcendental do conceito originário de verdade em Heidegger, Duits acusa Tugendhat de haver se prendido à perspectiva metafísica da Vorhandenheit. O objetivo deste artigo é indicar, com a ajuda dessa discussão, a questão fundamental da critica de Tugendhat que, como parte da literatura mostrou (LAFONT, 1994: SMITH, 2007), reside não tanto na exigência de uma explicação para a falsidade, mas muito mais na exigência de uma justificação para a transição semântica de 'verdade'. Após mostrar nas duas primeiras seções como, respectivamente. Dahlstrom e Duits não atingem o cerne da critica de Tugendhat, defendo na terceira seção minha interpretação da critica de Tugendhat contra certas reservas recentemente articuladas por Wrathall (2011). Concluo indicando a consonância dessa interpretação com a concessão de Heidegger em Das Ende der Philosophie und die Aufgabe des Denkens e apontando algumas questões pendentes.

Palavras-chave: Verdade. Heidegger. Tugendhat. Falsidade.

Abstract: The objections made by Daniel Dahlstrom (2001) and by Rufus Duits (2007) against Tugendhat's criticism of Heidegger's concept of truth are reconstructed in this paper. Both purport to defend Heidegger against Tugendhat's charges by showing that the most primordial concept of truth as unconcealment (Unverborgenheit) does account for falsehood. Roughly while Dahlstrom maintains that Tugendhat does not does justice to the transcendental character of Heidegger's primordial truth, Duits contends that Tugendhat is still attached to the metaphysical perspective of Vorhandenheit. The aim of this paper is to show that both contenders miss the decisive point in Tugendhat's critique, which lies, as part of the literature has shown (LAFONT, 1994; SMITH, 2007), not so much in the demand for an explanation of falsehood, but rather in the demand for a justification for the semantic transition of 'truth'. After showing in the first two sections how respectively Dahlstrom and Duits miss the core of Tugendhat's criticism, I defend in the third section my interpretation of Tugendhat's critique against certain reservations recently articulated by Wrathall (2011). I conclude by both pointing out the alignment between my proposal and Heidegger's own concession in Das Ende der Philosophie und die Aufgabe des Denkens and indicating some pending issues. Keywords: Truth. Heidegger. Tugendhat. Falsehood.

Resumen: En este artículo se recogen las objeciones de Daniel Dahlstrom (2001) y Rufus Duits (2007) a la critica de Tugendhat (1970) a la tesis heideggeriana de que el concepto primordial de verdad consiste en la noción de no-velamiento

\footnotetext{
1 O presente trabalho é fruto de pesquisa iniciada durante o doutorado no PPGF-UFRJ - financiada pelas agências CNPq e CAPES - e consiste em versão atualizada da posição defendida na tese de doutorado (cf. TADDEl, 2014).

Universidade Federal do Rio de Janeiro (UFRJ), Rio de Janeiro, RJ, Brasil.
} 
(Unverborgenheit). De diferentes maneras, ambos autores sostienen que Heidegger, a diferencia de las acusaciones de Tugendhat, seria capaz de dar cuenta de la falsedad. En líneas generales, mientras Dahlstrom propone que Tugendhat no apreció el carácter trascendental del concepto originario de verdad en Heidegger, Duits acusa a Tugendhat de haberse aferrado a la perspectiva metafisica de Vorhandenheit. El objetivo de este artículo es indicar, con la ayuda de esa discusión, la cuestión fundamental de la crítica de Tugendhat que, como parte de la literatura mostró (LAFONT, 1994; SMITH, 2007). reside no tanto en la exigencia de una explicación para la falsedad, pero mucho más en el requisito de una justificación para la transición semántica de 'verdad'. Después de mostrar en las dos primeras secciones como, respectivamente, Dahlstrom y Duits no llegan al corazón de la crítica de Tugendhat, defiendo en la tercera sección mi interpretación de la crítica de Tugendhat contra ciertas reservas recientemente articuladas por Wrathall (2011). Concluyo señalando la coherencia de esta interpretación con la concesión de Heidegger en Das Ende der Philosophie und die Aufgabe des Denkens y señalando algunas cuestiones pendientes.

Palabras clave: Verdad. Heidegger. Tugendhat. Falsedad.

\section{Introdução}

Desde a critica de Tugendhat $^{3}$ (1970, 1993) à proposta de Heidegger de que o conceito de verdade como desvelamento é o conceito mais originário de verdade, uma estratégia de defensores de Heidegger tem sido a de mostrar que Heidegger teria, sim, fornecido de modo satisfatório um conceito de falsidade. Gethmann (1993), por exemplo, propôs que se poderia definir o conceito de falsidade em Ser e Tempo recorrendo-se a critérios pragmáticos. Em Taddei (2019), mostra-se que Gethmann, ao fim e ao cabo, não propõe um conceito pragmático de verdade - supostamente mais originário que o conceito tradicional como adequação -, mas meramente uma caracterização pragmática desse conceito tradicional, de modo que sua refutação da crítica tugendhatiana não é lograda. Neste artigo, argumentarei que também as tentativas de Dahlstrom (2001) e de Duits (2007) de rejeitar a critica de Tugendhat fracassam. Ainda que de modos diferentes, Dahlstrom (2001) e Duits (2007) também pretendem mostrar que Heidegger deu conta da falsidade no âmbito de seu conceito mais originário de verdade. A discussão dessas objeções a Tugendhat é instrutiva, pois servirá ao objetivo central desse artigo: mostrar que a questão fundamental da critica de Tugendhat reside, como parte da literatura mostrou (LAFONT, 1994: SMITH, 2007), na exigência de uma justificação para a transição semântica de "verdade". Na primeira seção, argumentarei que Dahlstrom fornece uma interpretação de Heidegger que, apesar de suas muitas virtudes, (i) não condiz com evidências textuais, (ii) não responde a nenhuma das acusações de Tugendhat satisfatoriamente e (iii) passa por cima do que proponho ser o ponto fundamental de Tugendhat ao caracterizá-lo como a "acusação menor" de Tugendhat. Tendo considerado o ponto decisivo já sob a formulação razoavelmente satisfatória de Dahlstrom, passo à objeção de Duits que, se tem o mérito de fazer mais jus aos textos de Heidegger e de Tugendhat, peca por flagrantemente pressupor aquilo que a crítica de Tugendhat demanda que seja demonstrado. Na terceira seção, contra breves argumentos recentemente articulados por Wrathall (2011), defendo essa interpretação da questão fundamental da critica de Tugendhat. Nas considerações finais, indico a consonância dessa interpretação com uma concessão tardia feita por Heidegger em Das Ende der Philosophie und die Aufgabe des Denkens e aponto questões pendentes dessa discussão.

\section{Princípio da bivalência e non sequitur: a objeção de Dahlstrom}

No quinto capitulo de Heidegger's Concept of Truth, Daniel Dahlstrom (2001) reconstrói a crítica de Tugendhat à tese de Heidegger de acordo com a qual o sentido de verdade originário consistiria no desvelamento 4 (Unverborgenheit), e propõe

\footnotetext{
3 Refiro-me aqui com a expressão "crítica de Tugendhat" à crítica que esse faz às teses de Heidegger sobre verdade. Importa aqui o Tugendhat comentador de Heidegger e Husserl e não tanto o Tugendhat filósofo de obras posteriores; por isso, as críticas posteriores de Tugendhat a Heidegger - como aquela ensaiada em Selbstbewusstsein und Selbstbestimmung (Tugendhat, 1979) - não estarão em tela. Cf. abaixo n. 5 e n. 6 e Taddei (2019).

4 Ao longo de sua carreira, Heidegger conferiu muitos nomes a esse sentido mais originário de verdade: "descobrir" (Entdecken), "descerramento" (Erschlossenheit), "abertura" (Offenheit), "clareira" (Lichtung), dentre outros. Embora não sejam equivalentes e muito do percurso de Heidegger possa ser medido justamente pelas pequenas mudanças que vão de uma a outra versão desse conceito mais originário de verdade, trabalho aqui com o termo "desvelamento" (Unverborgenheit) para exprimir grosso modo esse sentido que Heidegger entende ser o mais primordial de verdade. Na discussão com as contestações de Dahsltrom e Duits que empreendemos aqui, é especialmente importante a noção, presente em Ser e Tempo, de descerramento, frequentemente traduzida por 'abertura' e aqui traduzida por 'descerramento'.
} 
uma contestação a essa crítica. Sua reconstrução é instrutiva, pois, embora não exaustiva5, busca fazer jus ao caráter incisivo da crítica de Tugendhat (DAHLSTROM, 2001, p. 398). Para fins de apresentação da crítica tugendhatiana, retomo nessa seção a reconstrução de Dahlstrom.

Fundamentalmente, Dahlstrom distingue na critica de Tugendhat duas acusações, a saber, uma acusação principal (main charge) e uma acusação menor (lesser charge) (DAHLSTROM, 2001, p. 398-403). A acusação principal seria a de que Heidegger perde de vista o sentido específico da verdade. Dahlstrom, seguindo de perto Tugendhat, entende que essa perda se daria porque Heidegger não retém nada semelhante à distinção feita por Husserl entre meras intenções e intenções preenchidas - a diferença entre a mera doação e a doação da coisa nela mesma (DAHLSTROM, 2001, p. 403). Com isso, o termo "descobrir" no $\S 44$ (a) torna-se ambíguo, de modo que a paulatina eliminação dos critérios de verdade e falsidade nas formulações de Heidegger, tal como Tugendhat a reconstrói, ${ }^{6}$ passa despercebida (TUGENDHAT, 1970, p. 333). Dahlstrom conclui que o conceito de verdade como desvelamento, na visão de Tugendhat, não respeitaria o que Dahlstrom denomina de principio de bivalência, isto é, o principio segundo o qual a definição do verdadeiro deve abrir espaço para a definição do falso.

A acusação menor de Tugendhat, segundo Dahlstrom, seria a de que Heidegger incorreria em um non sequitur (DAHLSTROM, 2001, p. 395. 398-403). Em termos gerais: do fato de que $A$ seja uma condição necessária de $B$ não se segue que A seja o fenômeno originário de B. Aplicado a Ser e Tempo: do fato de que o descerramento (Erschlossenheit) seja condição de possibilidade da verdade enunciativa, não se segue que ele seja a verdade originária. É certo que o fenômeno do descerramento é condição de possibilidade para a descoberta dos entes em geral e, por isso, também dos entes revelados no âmbito da verdade enunciativa; disso não se pode concluir, no entanto, que o descerramento seja o fenômeno originário da verdade (TUGENDHAT, 1970, p. 297).

Contra a acusação principal, Dahlstrom sustentará que o conceito primordial de verdade como descerramento atende, sim, ao princípio de bivalência; os critérios para a distinção entre o verdadeiro e o falso não teriam sido perdidos no âmbito da verdade originária. Contra a acusação secundária, Dahlstrom, reconhecendo o caráter falacioso do argumento acima esboçado, buscará qualificá-lo de modo a torná-lo válido. A estratégia de Dahlstrom é mostrar de que modo Heidegger, assim como Kant, defende o sentido mais primordial de verdade como uma veritas transcendentalis, lançando mão para tanto do que contemporaneamente se denomina "argumento transcendental". Nesse sentido, Dahlstrom assimila a crítica de Tugendhat à crítica de Stroud aos argumentos transcendentais, de acordo com a qual esses não distinguem suficientemente verdade de sentido (Dahlstrom, 2001, p. 419, n.17). Ambas as contestações - à acusação principal e à acusação menor - confluem para a posição final de Dahlstrom com relação a Tugendhat, a saber, a de que:

Heidegger interpreta a verdade originária como o descerramento que jaz anteriormente a todo e qualquer enunciado e assim a toda e qualquer possibilidade

\footnotetext{
5 Ao todo, são seis, não apenas duas, as acusações de Tugendhat a Heidegger no que concerne à verdade, em seu Der Wahrheitsbegriff bei Husserl und Heidegger: (i) o abandono da ideia de uma consciência crítica; (ii) a perda dos critérios de verdade no âmbito da verdade enunciativa (Aussagenwahrheit); a impossibilidade de distinguir o verdadeiro do falso em enunciados; (iii) a perda dos critérios de verdade no âmbito do conceito de desvelamento (Unverborgenheit); a impossibilidade da falsidade no âmbito do desvelamento; (iv) a rejeição da distinção entre conteúdo judicativo (Urteilsgehalt) e ato de julgar (Urteilsvollzug); recusa na distinção entre um juizo em espécie e a realização fática de um juizo; (v) relativismo da abertura (Offenbarkeit); (vi) o não cumprimento da Minimalbedingung (condição mínima) de um conceito de verdade em geral, também chamado, na recente literatura secundária, de argumento do direito (the rights argument): o problema da transição semântica entre um e outro conceito de verdade. No que concerne a este artigo, em que parto da reconstrução de Dahlstrom, as acusações (ii), (iii) e (vi) estarão no centro da discussão.

6 A critica de Tugendhat está apoiada textualmente em uma análise detida do $\S 44$ (a) em que ele mostra como as três definições fornecidas por Heidegger de verdade enunciativa representam o abandono paulatino dos termos que expressam os critérios para a distinção entre o verdadeiro e o falso - na segunda definição, a expressão "assim... como...", que estava presente na primeira, desaparece; e na terceira definição, a expressão "ente nele mesmo", constante na segunda definição, é alijada. Apenas através da eliminação dessas duas expressões, consegue Heidegger alcançar a terceira definição de verdade, que faz equivaler a verdade do enunciado com o seu ser-descobridor. Cf. Tugendhat (1970, p. 331-333): Heidegger (2001, p. 218). Para uma exposição mais detalhada dessa análise, ver Taddei (2019).

Para a crítica na sua versão original, ver STROUD, 1968, p. 241-256.
} 
de verdade ou falsidade enunciativa. $\mathrm{Na}$ medida em que a interpretação toma a forma de um argumento transcendental [...], a verdade originária é entendida em enunciados para os quais há contrários. Portanto, a verdade enunciativa, ou, mais precisamente, o critério de bivalência do discurso com sentido sobre a verdade. no qual Tugendhat corretamente insiste, permanece em vigor (DAHLSTROM, 2001, p. 423, tradução nossa). ${ }^{8}$

Dahlstrom pretende, em suma, que sua reconstrução do argumento transcendental de Ser e Tempo invalide a acusação de non sequitur. evidenciando que o descerramento pode ser considerado o fenômeno originário de verdade. Esse argumento, por sua vez, envolveria enunciados para os quais há contrários - o que garantiria o caráter de bivalência no âmbito da verdade originária. Nesse sentido, escreve Dahlstrom:

Heidegger articula o descerramento da temporalidade (enquanto sentido do ser-aqui ${ }^{9}$ em juizos temáticos e enunciados - não enunciados "mundanos" ou apofânticos, mas através de enunciados fenomenologicamente categoriais, enunciados existenciais - e o faz precisamente porque há concepções alternativas (juizos, asserções, enunciados) sobre o sentido de ser (DAHLSTROM, 2001, p. 423, tradução nossa). ${ }^{10}$

Os contrários, antes referidos, são os enunciados que versam sobre concepções alternativas a respeito do sentido de ser. Assim, os enunciados que formariam a argumentação transcendental de Ser e Tempo, destinados, é certo, não a verdades "mundanas", mas a fazerem parte da fenomenologia existencial, são bivalentes porque podem descrever o descerramento segundo um sentido de ser alternativo àquele que Heidegger entende ser o próprio do Dasein -assim, poderiam ser adequados ou não adequados. Esse fato legitimaria a tese heideggeriana de acordo com a qual o descerramento é o fenômeno mais originário de verdade frente à crítica tugendhatiana de que o conceito de descerramento - e semelhantes - não seria bivalente.

Embora Dahlstrom reconstrua de modo geral corretamente as duas acusações mais discutidas da crítica de Tugendhat, seus dois argumentos para contestá-las, a meu ver, não são exitosos: tanto não se consegue mostrar que o sentido originário de verdade, tal como concebido em Ser e Tempo como descerramento, admite o principio de bivalência, como não é o caso que, através da atribuição a Heidegger de um argumento transcendental, se pudesse rejeitar a acusação de non sequitur. Nos dois pontos, ademais, é o caso que Heidegger nem propõe um conceito de verdade bivalente, nem deve ser lido como oferecendo um argumento transcendental. Em outras palavras: não apenas os argumentos de Dahlstrom contra as duas acusações são malsucedidos, também as teses que eles propõem fundamentar são incorretamente atribuidas a Heidegger.

O seu argumento contra a acusação principal, o de que o conceito de descerramento admite bivalência porque os enunciados que o descrevem têm contrários é, como mostrou Overgaard (2002, p. 88), claramente problemático. Confunde-se o nível do fenômeno descrito e o nivel da descrição de fenômeno. O fenômeno descrito é aqui o descerramento como sentido originário de verdade. Para mostrar que esse sentido de verdade admite bivalência, Dahlstrom argumenta que enunciados contrários sobre esse fenômeno são possiveis. Do fato de haver juizos alternativos ou contrários a respeito do sentido de ser, que permitem outras descrições do descerramento não se segue que o próprio descerramento seja bivalente. Em outras palavras, Dahlstrom quer emprestar um suposto caráter

\footnotetext{
8 Do original: Heidegger interprets the original truth as the disclosedness that lies in advance of every proposition and thereby every possibility of propositional truth and falsity. Insofar as the interpretation takes the form of a transcendental argument [...], the original truth is construed in assertions for which there are contraries. Thus, propositional truth, or more precisely, the bivalency criterion of meaningful talk about truth, on which Tugendhat rightly insists, is still in force.

9 Dahlstrom traduz o alemão 'Dasein' pelo inglês 'being-here', em vez do usual 'being-there', fornecendo exemplos célebres sugestivos de que o alemão 'da' é mais bem traduzido para o inglês por 'here' do que por 'there' (ver DAHLSTROM, 2001, p. xxv, n.1). Essa opção de tradução, contudo, não é de especial importância para o presente artigo - por mera fidelidade ao original do comentário de Dahlstrom, escolhemos traduzir 'being-here' por 'ser-aqui'.

10 Do original: Heidegger articulates the disclosedness of timeliness (as the sense of being-here) in thematic jugdements and assertions - not "worldly" or "apophantic", but rather "phenomenologically categorial" or "existential" assertions - and he does so precisely because there are alternative conceptions (judgements, assertions, propositions) about the sense of being.
} 
bivalente de enunciados fenomenológicos sobre o descerramento como fenômeno originário de verdade ao próprio fenômeno do descerramento que está sendo descrito. Ao invés disso, o que teria de ser mostrado é que o fenômeno do descerramento ele próprio, na medida em que. segundo o Heidegger de Ser e Tempo, perfaz o conceito mais originário de verdade, admite o princípio da bivalência.

A própria tese de que o descerramento envolve algum tipo de bivalência relevante para a questão levantada por Tugendhat é, todavia, altamente questionável. Pode-se ser levado a crer nessa tese pelas diversas passagens do $\S 44$ (b) de Ser e Tempo - e da obra de Heidegger em geral em que Heidegger menciona certo caráter de velamento envolvido no desvelamento dos entes no âmbito do descerramento: Duits, inclusive, emprega parcialmente essa estratégia que, como veremos à frente, também parte de uma apreensão equivocada da crítica de Tugendhat. De todo modo, em passagens como a seguinte, da preleção de inverno 1925/26. Lógica: A questão da verdade. Heidegger, comentando Aristóteles, claramente caracteriza o acontecimento de descobrir como não envolvendo nenhum tipo de encobrir:

De acordo com isso obteve-se um modo de descoberta (Entdeckung), que se destaca dos outros, na medida em que essa verdade não tem nenhum oposto, nenhuma falsidade: mais precisamente, essa verdade é um descobrir para o qual não existe um encobrir (Verdecken) (HEIDEGGER, 1995, p. 182. tradução nossa). ${ }^{11}$

É certo que nessa passagem sinóptica, que antecipa as breves passagens do $\S 7$ (b) e do $\S 44$ (b) de Ser e Tempo sobre o mesmo tema, Heidegger está comentando as sensações e apreensões simples de Aristóteles e atribuindo a essa caracterização aristotélica da verdade um resquício do sentido de verdade como desvelamento. Mas também é o caso que Heidegger pretende que o próprio descerramento envolva certo caráter de simplicidade. Assim. parece que também o descerramento, no que se refere à sua dimensão de simples ver das coisas, se resolva em termos de um dar-se e um não se dar, o que é estruturalmente distinto da bivalência enunciativa, que envolve a distinção entre dois modos de descoberta dos entes, a descoberta dos entes tout court e a descoberta dos entes neles mesmos. Ao discutirmos as objeções de Duits adentraremos essa questão em mais detalhes. Por ora, vejamos por que também a objeção de Dahlstrom à acusação por ele definida como menor não apenas não é bem-sucedida, como é mesmo incompativel com Heidegger.

Dahlstrom busca defender Heidegger da acusação de cometer um non sequitur apontando para o fato de que o descerramento é entendido por Heidegger como verdade transcendental. A estratégia de Dahlstrom envolve um passo semelhante ao de Gethmann (1993): qualificar a caracterização transcendental de Ser e Tempo, de modo a justificar a tese de que o descerramento perfaz o sentido mais originário de verdade como veritas transcendentalis. Mais exatamente, trata-se de qualificar a relação de condição de possibilidade entre a verdade enunciativa e o fenômeno do descerramento (DAHLSTROM, 2001, p. 398-403). Assim, Dahlstrom distingue três usos de 'sentido' em Heidegger: um primeiro, o sentido original existencial-hermenêutico: um segundo, o sentido derivado existenciáriohermenêutico; e um terceiro, o sentido derivado apofântico. No primeiro uso de 'sentido', temos o plano do horizonte último no qual o Dasein projeta suas possibilidades, o descerramento. No terceiro, temos a dimensão de significado de juizos e enunciados. As relações de condição de possibilidade são claras: o primeiro 'sentido' é condição de possibilidade do segundo 'sentido', que, por sua vez, é condição de possibilidade do terceiro sentido. Esse (o como apofântico), por sua vez, é necessário para determinar qualquer verdade enunciativa - ai teriamos, em toda a complexidade de Ser e Tempo, reconstruido como o descerramento torna possivel a

11 Do original: Demnach ist jetzt eine Weise von Entdeckung gewonnen, die sich vor anderen ausnimmt, was sich darin zeigt, daß diese Wahrheit kein mögliches gegenteil im Sinne einer Falschheit hat, genauer: ein Entdecken ist, für das es keine Verdeckung gibt. 
verdade enunciativa. Ora, essa apresentação mais minuciosa das relações de condição de possibilidade em nada altera a questão: ainda podemos nos perguntar o que autoriza Heidegger a empregar o termo "verdade" para o primeiro sentido de sentido, isto é, para o descerramento como horizonte último de revelação dos entes. ${ }^{12}$

Uma vez estabelecida a complexidade das relações de condições de possibilidade das relações de fundação, para usar o jargão fenomenológico - Dahlstrom pretende dar o passo decisivo na seguinte passagem:

Heidegger nomeia essa verdade "a mais original" porque ela é o horizonte de toda e qualquer outra "verdade", isto é, porque ela é necessariamente [...] pressuposta [...] por toda outra verdade. Ele [Heidegger] não faz a inferência ilícita de que o descerramento é em alguns aspectos a verdade originária porque ele é uma condição para descobrir as coisas e porque a verdade enunciativa surge do processo de descobrir as coisas. Ao invés disso, Heidegger caracteriza o descerramento como "a verdade original" porque ele se revela como ele é nele mesmo (e se deixa interpretar desse modo) e porque é precisamente esse autodescerramento que co-constitui o processo através do qual os entes são descobertos ou velados (DAHLSTROM, 2001, p. 402, tradução nossa). ${ }^{13}$

É fácil ver que na passagem acima o passo decisivo envolve uma petição de princípio. Vejamos por quê. A complexidade das relações de fundação é mobilizada para clarificar que mesmo na descoberta apofântica o descerramento é o horizonte último de sentido - uma tese contra a qual a critica de Tugendhat nada tem a dizer. A essa tese, que não é suficiente para responder à acusação de non sequitur, é adicionada a sugestão de que, sendo o descerramento um acontecimento de autorrevelação de si próprio, ele deve ser considerado o fenômeno mais originário.
Claro está que a questão da acusação menor de Tugendhat é justamente por que o acontecimento de revelação dos entes deve ser considerado a verdade originária, ou até mesmo verdade em geral. Ao dizer que o descerramento se revela a si próprio e diz respeito a um âmbito básico de autorrevelação das coisas, Dahlstrom está pressupondo que esse acontecimento possa ser chamado de verdade, quando, de fato, isso é o que está em questão pela acusação menor. Também aqui vemos o problema que veremos em mais detalhes quando adentrarmos as objeções de Duits.

Além do fato de a argumentação de Dahlstrom ser insuficiente para rejeitar o non sequitur, há nela um problema adicional: ao aproximar Heidegger de Kant e supor que se trata em Heidegger de um argumento transcendental, Dahlstrom perde de vista a distinção, traçada por Mohanty, entre dois modelos de filosofia transcendental: prinzipientheorethische evidenztheoretisch. De um lado, há uma filosofia transcendental prinzipientheorethisch, de tipo kantiano ou neo-kantiano, que se volta para alegações cognitivas e busca principios a priori. Nesse modelo de filosofia transcendental, são necessários argumentos transcendentais para responder à questão do direito de aplicação de categorias à experiência. De outro lado, há uma filosofia transcendental evidenztheoretisch, que, dispensando esse tipo de argumento ou prova, se basta em uma reflexão apropriada que visa clarificar sentidos ou "o mundo como estrutura de significados" (MOHANTY, 1985, p. 215) ${ }^{14}$. Embora Mohanty trace essa distinção tendo em vista a fenomenologia de Husserl, claro está que ela se aplica sem dificuldade à fenomenologia de Ser e Tempo, uma vez que é parte da fenomenologia de Heidegger a elucidação dos sentidos de ser que já sempre estruturaram a compreensão de ser do Dasein para que entes venham ao seu encontro. Em

12 Parte da literatura que responde a Tugendhat o faz, ao menos em parte, através dessa estratégia. Também incidem nesse ponto Gethmann (1993) - como exposto em Taddei (2019) -, Wrathall (2002), e, na bibliografia no Brasil, Ribeiro (2018, p. 23).

13 Do original: Heidegger labels this truth the "most original" because it is the horizon for every other "truth", that is, because it is necessarily [...] presupposed by [...] every other truth. He thus does not make the illicit inference that disclosedness is in certain respects the original truth because it is a condition for uncovering things and because propositional truth arises out of this process of uncovering things. Instead Heidegger characterizes disclosedness as "the original truth" because it reveals itself as it is in itself (and allows itself to be so interpreted) and because it is precisely this self-disclosing that co-constitutes the process whereby entities are uncovered or concealed. 14 Mohanty desenvolve essa distinção com o objetivo de comparar o modelo de filosofia de Kant e de neo-kantianos com a fenomenologia de Husserl. Que o conceito de filosofia transcendental evidenztheoretisch possa ser estendido a Heidegger, é algo que foi mostrado por Crowell no capitulo 9 de Husserl, Heidegger and the Space of Meaning (2001), em que a autor reconstrói a discussão entre Husserl e Heidegger em torno do verbete da Enciclopédia Britânica. 
outros termos: o deslize de Dahlstrom apontado por Overgaard do descerramento para a descrição do descerramento ocorre no contexto da tentativa de aproximar Kant e Heidegger: assim como Kant teria que provar a verdade transcendental de um juízo que exprime um principio a priori (DAHLSTROM, 2001, p. 422), o que pressupõe que esse principio possa ser falso, assim também em Heidegger as descrições do descerramento poderiam ser feitas segundo concepções alternativas (DAHLSTROM, 2001, p. 423). Não há, contudo, em Ser e Tempo, nada como um argumento transcendental: Heidegger não busca refutar o cético, nem provar a validade de princípios a priori, mas sim elucidar um "espaço de sentido", para usar a expressão cara a Crowell, que é condição de possibilidade do encontro dos entes ${ }^{15}$. Se Heidegger rejeita a tese cética por essa envolver uma posição que, em sua facticidade, implica o desespero do suicídio que nega o Dasein e a verdade (HEIDEGGER, 2001, p. 229), isso não pode ser porque Heidegger houvesse argumentado, isto é, provado, que o ceticismo está errado. Assim como o discurso sobre "verdades eternas" é problemático para Heidegger (2001, p. 227), também o é o cético. Ainda que se possa reconhecer, como o faz Dahlstrom, certa semelhança entre Kant e Heidegger no fato de rejeitarem tanto uma posição dogmática, quanto uma posição cética, não há passagem mais inequivoca a respeito do distanciamento de Heidegger com relação a uma posição kantiana do que a célebre e frequentemente citada passagem do $\$ 43$ concernente ao escândalo da filosofia (HEIDEGGER, 2001, p. 205). Se Heidegger quer nos convencer de que o escândalo da filosofia é que se espere e que se tente provar a existência do mundo externo, uma prova que tipicamente é realizada através do que o século $X X$ criticou sob a rubrica de "argumento transcendental", isso é apenas possivel porque Ser e Tempo, enquanto filosofia transcendental, não está fornecendo um argumento dessa natureza, mas sim levando a cabo elucidações de um espaço de sentido que permitem tornar a expectativa de tal argumento inócua.
Argumentou-se nessa seção que as objeções de Dahlstrom não abalam a crítica de Tugendhat nas duas acusações desta crítica que o americano destaca, a saber, na acusação principal, de que Heidegger teria perdido o fenômeno específico da verdade, e na acusação menor, de que Heidegger teria incorrido em um non sequitur. Assim, mostramos que não há razões para se acreditar em bivalência na noção de descerramento - o que elaboraremos em mais detalhes na discussão com Duits - e que a contestação do non sequitur, ao envolver a ideia de que há um argumento transcendental em Heidegger, é incompativel com o modelo fenomenológico de filosofia transcendental. A lição mais importante dessa discussão está, todavia, na interessante reconstrução de Dahlstrom da crítica de Tugendhat - embora não exaustiva, a separação das duas acusações é relevante e peca apenas por inverter a prioridade das acusações: é a acusação de non sequitur. embora não formulada exatamente desse modo, que é a decisiva, ao passo que a acusação de perda do fenômeno específico da verdade é secundária respectivamente a essa. Na seção 3. elaboraremos esse ponto em mais detalhes.

Na próxima seção passaremos às objeções de Duits a Tugendhat. Como Dahlstrom, Duits quer nos convencer de que Heidegger é capaz de dar conta da falsidade no âmbito da verdade mais originária. Diferentemente de Dahlstrom, todavia, Duits parece se alinhar a uma interpretação mais ortodoxa de Heidegger: enquanto Dahlstrom aproxima Heidegger de Kant e a crítica de Tugendhat a discussões da chamada tradição analítica, Duits opta por contestar Tugendhat de modo hermeneuticamente mais sensivel a Heidegger, isto é, por uma contestação que se baseia em uma exegese que busca inserir as teses de Heidegger sobre a verdade no todo de sua obra, ou de seu caminho de pensamento, como se costumou formular. Assim referências à filosofia transcendental estão ausentes na contestação

15 Ademais, se é possivel rejeitar assim que Heidegger tenha empregado qualquer tipo de argumento transcendental, então podemos rejeitar também como pouco relevante a aproximação, sugerida por Dahlstrom, entre a crítica de Tugendhat a Heidegger e a crítica de Stroud aos argumentos transcendentais. Por mais que ambas possam ser entendidas como consistindo na confusão entre sentido e verdade, o fato de que em Heidegger não haja nada como um argumento transcendental torna a referência a Stroud ociosa. 
de Duits, como é o caso em interpretações que entendem o caráter transcendental de Ser e Tempo como consistindo meramente em uma estação intermediária, a ser superada, do caminho de pensamento de Heidegger.

\section{Falsidade como modo da verdade: a objeção de Duits}

Em On Tugendhat's Analysis of Heidegger's Concept of Truth. Duits (2007) interpreta a critica de Tugendhat como consistindo em duas acusações: a de que Heidegger incorreria em uma ambiguidade ao definir seu conceito de verdade, e a de que Heidegger não fornece um conceito adequado de falsidade. Contra essas acusações, Duits sustenta, em primeiro lugar, que não há ambiguidade no conceito de verdade de Heidegger - trata-se, antes, apenas de um conceito, com duas aplicações diferentes - e, em segundo lugar, que Heidegger, com efeito, fornece um conceito adequado de falsidade, no contexto de um conceito pós-metafísico de verdade. A falha fundamental da leitura de Tugendhat estaria justamente em "recusar-se a dar o passo decisivo para o horizonte no qual a possibilidade de uma crítica fundamental-ontológica, pós-metafísica do conceito de verdade estaria primeiramente disponivel" (DUITS, 2007, p. 220). A estratégia de Duits é, assim, a de mostrar que Tugendhat, por estar preso à compreensão de ser como Vorhandenheit(ser simplesmente dado), presença constante, stasis (DUITS, 2007, p. 212), não é capaz de compreender a superação que Heidegger busca realizar da noção tradicional de verdade. Também nesse sentido, Duits vincula a crítica de Tugendhat a uma negligência do papel do existencial da decadência (Verfallen), responsável justamente por uma tendência do Dasein a se compreender a partir do sentido de ser como Vorhandenheit (DUITS, 2007, p. 215).

De início, é importante conceder que Duits está ao menos parcialmente correto em identificar o fato de que a crítica de Tugendhat, se não está integralmente comprometida com a compreensão de ser como ser simplesmente dado, assume o risco de um atrelamento a esse sentido de ser em sua interpretação de Ser e Tempo. Independentemente de a Vorhandenheit ser ou não representativa de uma perspectiva metafísica, respectivamente à qual Heidegger proporia uma ontologia pós-metafísica, o próprio Tugendhat reconhece o perigo que sua critica assume, quando, ao comentar sua exigência para qualquer conceito fenomenológico de verdade. de diferenciação de um dar-se do objeto para um dar-se do objeto nele mesmo, afirma ser "possivel que a reflexão acima li.e., a reflexão que propõe essa exigência] não tenha conseguido se libertar suficientemente do preconceito da objetualidade [Gegenständlichkeit]" (TUGENDHAT, 1970, p. 198). Esse risco não é casual, mas diz respeito, proponho eu, ao passo decisivo de sua crítica ao conceito de verdade de Heidegger. Mesmo reconhecendo o papel central desempenhado pela demonstração do caráter derivado da Vorhandenheit como sentido de ser, Tugendhat ergue a seguinte exigência no início do $\S 15$ de seu clássico comentário a Husserl e Heidegger:

Tanto em Ser e Tempo, quanto nos escritos posteriores, onde quer que ele tenha desenvolvido seu conceito de verdade. Heidegger com razão constantemente partiu da verdade enunciativa. Pois, ainda que ele queira mostrar que há um conceito de verdade mais amplo e até mais originário, a legitimidade de uma definição [Bestimmung] de verdade tem que se verificar de inicio junto àquele sentido de verdade que é o mais corrente e é universalmente reconhecido. Que um conceito de verdade se ajuste à verdade enunciativa é a condição mínima [Minimalbedingung] que ele tem que cumprir, se é que ele é em geral um conceito de verdade [wenn er überhaupt ein Wahrheitsbegriff sein soll] (TUGENDHAT, 1970, p. 331, tradução nossa). ${ }^{16}$

A exigência não é simplesmente, vale dizer, imposta por Tugendhat, mas depreendida do fato

\footnotetext{
16 Do original: Mit Rech ist Heidegger sowohl in SuZ als auch in den späteren Schriften, wo immer er seinen Wahrheitsbegriff entwickelt hat, stets von der Aussagewahrheit ausgegangen. Denn wenngleich er zeigen will, daß es einen weiteren und sogar ursprünglicheren Wahrheitsbegriff gibt, muss sich doch die Rechtmäßigkeit einer Wahrheitsbestimmung zunächst an demjenigen Sinn von Wahrheit ausweisen, der der geläufigste und allgemein annerkannte ist. Daß ein Wahrheitsbegriff auf die Aussagewahrheit paßt, ist die Minimalbedingung, die er erfüllen muss, wenn er überhaupt ein Wahrheitsbegriff sein soll.
} 
de que em diversos escritos Heidegger toma a concepção tradicional de verdade como ponto de partida para expor alguma versão da tese de que o sentido primordial de verdade reside no desvelamento. Note-se que a acusação de non sequitur, a acusação menor na reconstrução de Dahlstrom, mas aqui proposta como acusação mais importante, coincide com essa exigência: a inferência ilegítima segundo a qual, se há relações de fundação entre verdade enunciativa e descerramento, então o descerramento é o sentido mais originário de verdade, é propriamente o que nos leva erradamente a acreditar que essa exigência foi cumprida. Contra ela, Dahlstrom propõe reconstruir o que ele entende ser o argumento transcendental de Heidegger. $\mathrm{Na}$ seção anterior, mostrei razões para crer que, mesmo que Ser e Tempo possa ser lido como uma filosofia transcendental, essa não é de nenhum tipo que demande um argumento transcendental. Embora frontalmente oposta a Tugendhat, nesse aspecto a resposta de Duits lhe é mais fiel que a de Dahlstrom: Duits entende, assim como Tugendhat, que se trata não de um argumento a ser fornecido por Heidegger, mas de uma análise conceitual, que mostre a relação entre os dois conceitos, a saber, o conceito "mais corrente" de adequação (para Duits, metafísico) e o conceito mais originário de desvelamento ou, como no caso de Ser e Tempo, o descerramento (para Duits, pós-metafísico). A exigência mínima não é outra senão a exigência de que não se esteja simplesmente incorrendo em uma equivocação: se queremos chamar o descerramento de "verdade", o que garante que não estejamos simplesmente usando o termo de modo equívoco, dado o sentido mais corrente e universalmente aceito? Caso se conclua que não há nada de comum entre um e outro conceito de verdade, então que sentido faz alegar que um é mais originário que outro? Caso se conclua, por outro lado, que há elementos em comum, a pergunta que se põe é justamente a respeito dessa relação entre esses conceitos e de como ela faculta a passagem do conceito mais corrente ao conceito mais originário.
É essa exigência de uma condição mínima que se traduz em uma explicação para a transição semântica de um a outro conceito de verdade que perfaz o passo decisivo da crítica de Tugendhat ao conceito de verdade de Heidegger. E é ela que torna significativas as outras acusações de Tugendhat, em especial para este artigo, a acusação de perda da falsidade. Eé, por fim, à luz dessa questão que poderemos ver que as objeções de Duits, a despeito da sensibilidade hermenêutica respectivamente a Heidegger e a despeito do fato de ele até mesmo abordar essa acusação mais fundamental, não conseguem enfraquecer a crítica de Tugendhat. Retomemos, agora em detalhe, as objeções de Duits a Tugendhat - ambas dizem respeito diretamente ao ponto em questão.

Sua primeira objeção é a de que Heidegger não incorre em nenhuma ambiguidade em seu conceito de verdade. A ambiguidade aqui é a ambiguidade entre dois sentidos de descobrir. que Tugendhat encontra na terceira formulação da verdade enunciativa, a saber: "O ser verdadeiro do enunciado deve ser entendido como seu ser-descobridor" (TUGENDHAT, 1970, p. 332334). ${ }^{17}$ Para Tugendhat, o caráter descobridor do enunciado pode significar, nessa passagem, tanto o caráter apofântico de todo e qualquer enunciado, quanto o caráter correto de enunciados que descobrem o ente tal como ele é nele mesmo. Note-se que Duits, de início, supõe que a ambiguidade no termo "descobrir" é a ambiguidade no termo "verdade", quando, de fato, o que está em questão para Tugendhat é se o termo "verdade" pode ser definido a partir de noções como as de descoberta ou descerramento. Uma passagem posterior, porém, indica que Duits tem clareza de que a acusação de ambiguidade no uso do termo 'descobrir' se insere na questão mais ampla que Tugendhat está levantando, qual seja, a questão a respeito da passagem do conceito tradicional de verdade para o conceito de verdade como desvelamento.

Nesse caso, o argumento de Tugendhat, apesar de sua própria apresentação, não deve ser entendido como se Tugendhat 
acusasse Heidegger de ambiguidade, mas sim em termos da alegação de que a manobra de derivação, que Heidegger aparentemente pressupõe desempenhar, a ponte pela qual Heidegger desliza entre as duas formulações acima, a fundação [grounding] do caráter descoberto específico da verdade proposicional na verdade original do descerramento enquanto tal é injustificado, ao menos nos termos do texto (DUITS, 2007. p. 211-212, tradução nossa). ${ }^{18}$

A ambiguidade do termo 'descobrir' é somente relevante porque ela permite a Heidegger, no $\S$ 44 (a), fazer a passagem do conceito tradicional de verdade para o conceito de verdade como desvelamento. Como vimos na discussão de Dahlstrom acima, uma exposição das relações de fundação entre verdade enunciativa e descerramento em nada nos ajuda nesse ponto. O que Duits propõe para resolver o problema da transição semântica é mostrar que não existem dois conceitos de verdade, mas apenas um, com duas aplicações, dois empregos diferentes.

Ao invés de haver dois conceitos diferentes aqui, nós temos dois empregos ou extensões diferentes do mesmo conceito, distinguidas pelo seu respectivo domínio - um, ôntico, outro, ontológico. Ambas as extensões se referem ao simples acontecimento de emergência do velamento ao desvelamento (DUITS, 2007, p. 212, tradução nossa). ${ }^{19}$

A estratégia de Duits é mostrar que a emergência do velamento para o desvelamento perfaz o único conceito de verdade de Heidegger: a verdade enunciativa é apenas um caso particular desse acontecimento. É essa noção eventual ${ }^{20}$ de verdade que constitui o cerne do conceito de verdade heideggeriano, respectivamente ao qual a verdade enunciativa é uma aplicação particular, bem como a descoberta de entes na lida cotidiana e o descerramento em geral. É propriamente esse processo, esse acontecimento que seria a verdade para Heidegger, de acordo com Duits. Ora, se há apenas um conceito de verdade, um conceito do acontecimento ek-stático de verdade, então não se poderia acusar Heidegger de fazer uma transição ilegítima de um a outro conceito de verdade. A dita transição entre um e outro conceito de verdade é considerada, então, uma transição entre "duas aplicações do mesmo conceito de verdade" (DUITS, 2007, p. 212-213).

Salta aos olhos que, frente à exigência de Tugendhat, a estratégia de Duits não consiste em outra coisa senão em pressupor o que deveria ser demonstrado. Duits supõe que se pode aplicar o termo 'verdade' para designar o acontecimento ek-stático de desvelamento e reinterpreta as passagens à luz dessa aplicação, ao passo que o exigido por Tugendhat é que se explique justamente essa aplicação frente ao uso, mais corrente e aceito de modo geral, de 'verdade' para designar correspondência. De nada nos serve a afirmação de Duits de que também na correspondência o evento ek-stático do desvelamento está em jogo - pois a pergunta tugendhatiana aí seria: e por que se deve aceitar que esse aspecto defina - e mesmo de modo mais originário - a verdade? O que Tugendhat demanda é que, frente ao conceito mais corrente de verdade, o qual, enquanto conceito, não inclui nada como uma noção de acontecimento ekstático, se evidencie que as noções de descoberta, de desvelamento também possam ser designadas de 'verdade.' Duits está ciente de que o conceito tradicional de verdade como correspondência não inclui nenhuma noção eventual - caso contrário, não poderia dizer que a tarefa de Heidegger é superar esse conceito de verdade, marcado pela Vorhandenheit. Duits conclui do seguinte modo a sua primeira objeção a Tugendhat:

\footnotetext{
18 Do original: In this case, Tugendhat's argument, despite his own presentation, should not be construed as charging Heidegger with ambiguity, but rather in terms of the claim that the derivative manoeuvre, which Heidegger apparently presumes to perform, the bridge across which Heidegger slips between the two formulations above, the grounding of the specific uncoveredness of propositional truth in the original truth of disclosure as such, is unjustified, at least in the terms of the text.

19 Do original: Rather than having two different concepts here, we have two different employments or extensions of the same concept distinguished by their target domain - one ontic, one ontological. Both extensions refer to the simple happening of emergence from concealment to unconcealment.

20 Claro está que com a expressão 'eventual' não se quer dizer aqui fortuito, casual, ocasional, mas sim o que é meramente relativo a acontecimento, evento. Em conformidade com trabalhos posteriores em torno do acontecimento apropriativo (Ereignis), a noção eventual de verdade diz respeito à noção de verdade como o acontecimento da emergência do velamento para o desvelamento.
} 
Parece, então, que a ambiguidade que Tugendhat professa encontrar na análise de verdade de Heidegger no $\S 44$ é ilusória, e aparece enquanto tal somente do ponto de vista da concepção tradicional de verdade - o que é precisamente aquilo que Sein und Zeit no todo pretende superar através da revelação de sua gênese ontológica (DUITS, 2007, p. 213, tradução nossa). ${ }^{21}$

Ora, se é possivel falar aqui de superação da concepção tradicional de verdade, isso é claramente indicativo de que não há nessa concepção nada como uma noção de acontecimento. E a questão de Tugendhat é justamente como evidenciar que, frente a esse conceito de verdade, algo como o desvelamento possa se justificar como um fenômeno de verdade. ou como fenômeno mais primordial de verdade. A tentativa de Duits de rejeitar a acusação de ambiguidade, ao traduzir a ambiguidade do descobrir como ambiguidade do termo 'verdade', faz transparecer que o que deveria ser provado - o direito de passar de um conceito tradicional de verdade para o conceito de desvelamento está sendo, de fato, pressuposto. ${ }^{22}$

Abordemos, agora, a segunda objeção de Duits a Tugendhat: a de que Heidegger é, sim, capaz de fornecer um conceito de falsidade no contexto de seu conceito mais originário de verdade. Sua estratégia para lidar com o problema da falsidade se insere naquela para lidar com a ambiguidade do conceito de descobrir: supondo a legitimidade do desvelamento como conceito de verdade, Duits pode agora recorrer às várias instâncias em que Heidegger caracteriza esse acontecimento como envolvendo algum tipo de velamento - como consistindo propriamente no "jogo de desvelamento e velamento" (DUITS, 2007. p. 215, tradução nossa). ${ }^{23}$ O erro de Tugendhat se desdobraria aqui na incapacidade de compreender que o conceito de verdade de Heidegger envolve a não verdade como parte integral da verdade - o velamento como parte integral do desvelamento; e essa concepção se contrastaria com a ideia de uma oposição completa entre verdadeiro e falso, supostamente vigente na concepção tradicional de verdade própria à metafísica. Esse seria o ponto pós-metafísico que Tugendhat, preso à Vorhandenheit, não estaria disposto a endossar, de acordo com Duits.

Por razões de espaço, deixo de lado aqui a questão do caráter metafísico ou pós-metafísico dessa discussão para me concentrar na ideia de Vorhandenheit enquanto tal, i.e., na ideia do sentido de ser que preside o aparecimento dos entes em modalidades teóricas. Como afirmo acima, Tugendhat parece assumir o risco de uma confrontação da proposta de Heidegger a partir de uma perspectiva que é a perspectiva teórica, que tradicionalmente supôs e elaborou versões da concepção tradicional de verdade. A tradição da teoria do conhecimento é parte do que Heidegger pretende superar, mas há um autor específico nessa tradição que é relevante para a crítica de Tugendhat e cuja relevância não foi apreciada pelas objeções de Duits: Husserl. A exigência de comprovação de qualquer conceito de verdade à luz do conceito tradicional de verdade é feita com o apoio das elucidações fenomenológicas que Husserl havia elaborado a respeito da adequação/correspondência em Investigações Lógicas e que Heidegger, no próprio $\S 44$, cita. É nessa elucidação que encontramos a distinção entre mera intenção e intenção em função de preenchimento, que Tugendhat

\footnotetext{
21 Do original: It seems, then, that the ambiguity Tugendhat professes to find in Heidegger's analysis of truth in $\S 44$ is illusory, and appears as such only from the standpoint of the traditional conception of truth - which is precisely that which SZ as a whole is intended to overcome by laying bare its ontological genesis.

22 É no âmbito dessa questão fundamental que a falsidade aparece como um problema para Tugendhat. No que concerne à verdade enunciativa, há uma clara oposição entre verdade e falsidade - uma oposição que Husserl descrevera fenomenologicamente com a ajuda dos conceitos de mera intenção e intenção de preenchimento para designar dois modos de doação dos entes. Quando Tugendhat denuncia que Heidegger havia perdido o conceito de falsidade, ele o faz à luz da questão da passagem da correspondência ao desvelamento - se estamos chamando de "verdade" algo para o qual não há nenhum sentido de se falar de falsidade, então como isso não é simplesmente um emprego equivoco de um termo? Nesse sentido, o recurso de Gethmann (1993) às preleções em que Heidegger tematiza as condições da falsidade enunciativa no âmbito de um comentário a Aristóteles em nada alteram o ponto fundamental de Tugendhat: Heidegger pode certamente ter reconstruido de modo satisfatório alhures as condições da falsidade enunciativa, mas parece ser obrigado a abandonar pontos centrais de uma caracterização da verdade enunciativa ao tentar fazer a transição do conceito de verdade enunciativa para o conceito de verdade como desvelamento (cf. GETHMANN, 1993; TADDEI, 2019).

23 Do original: play of disclosure and closure.
} 
acredita estar sendo desrespeitada na terceira definição de verdade do § 44 (a).

Trago o exemplo de Husserl para evidenciar que a tese de um jogo de velamento e desvelamento é absolutamente compativel com sua fenomenologia e, portanto, com a concepção tradicional de verdade. Parte do argumento de Duits, inclusive, envolve justamente a caracterização da verificação como identificação, uma herança husserliana de Heidegger (DUITS, 2007, p. 214). Para além do apelo ao contexto de verificação de enunciados, patentemente compativel com uma concepção tradicional de verdade, Duits recorre à noção heideggeriana de Verfallen. decadência, para indicar que o desvelamento envolve necessariamente um velamento (2007, p. 215-218). A menos que se suponha que uma noção correspondentista de verdade implica a tese de que nossos enunciados possam corretamente descrever de modo exaustivo a realidade - uma tese bastante exigente e de modo nenhum aceita de modo geral -, o mero fato de que Heidegger entenda que qualquer aparecimento dos entes é sempre parcial não torna sua fenomenologia incompativel com a concepção tradicional de verdade; isso tampouco nos responde por que a noção de desvelamento perfaz a noção mais originária de verdade.

É interessante notar que ao mesmo tempo que Duits sugere uma radical assimetria entre esses conceitos de verdade, ele observa que o conceito de verdade como desvelamento é capaz de explicar a verdade enunciativa - por essa ser, como dissemos, um caso da primeira. Com isso, ele pode inclusive explicar a falsidade própria à verdade enunciativa em termos desse jogo entre velamento e desvelamento. Na passagem em que retoma o exemplo da verificação de Heidegger, Duits assim descreve a falsidade enunciativa:

Na medida em que a proposição falsa é imediatamente direcionada para [...] seu objeto, ela deve ser concebida em termos de uma função descobridora. $O$ que a diferencia da proposição verdadeira é o fato de que ela dissimula seu objeto em seu enunciado sobre ele e nesse sentido é ao mesmo uma função encobridora, ocultadora (DUITS, 2007. p. 214, tradução nossa). ${ }^{24}$

Mas essa caracterização do enunciado falso como sendo descobridor e encobridor não é novidade para Tugendhat: o que Duits chama aí de caráter descobridor é o caráter apofântico do enunciado, na interpretação heideggeriana, isto é, o caráter de o enunciado, ao ser compreendido. estar direcionado intencionalmente ao objeto. E o caráter encobridor na passagem acima é aquele que se revela na comparação com um modo privilegiado de descoberta dos entes que, no caso da falsidade, revela que os entes visados no enunciado não são os entes neles mesmos. O problema decisivo para Tugendhat é que o discurso generalista sobre descobrir e encobrir, ao ser aplicado para a dinâmica própria da verificação do enunciado, funde duas possibilidades distintas: a de se direcionar a objetos em geral e a de se confirmar ou, conforme o caso, falsificar as pretensões de enunciados. É essa diferença que Tugendhat marca como diferença entre dois niveis de manifestação dos entes. Sem essa diferença husserliana, a própria elucidação fenomenológica da verificação/falsificação permanece vazia, e, para além disso, um lema como "a volta às coisas elas mesmas" e o apelo ao caráter intuitivo perdem, a princípio, seu lastro. Se, por um lado, o apelo à intuição em Ser e Tempo é tratado, em uma passagem decisiva, de modo inconclusivo (HEIDEGGER, 2001, p. 363, n. 1), por outro lado, a impossibilidade de explicação da verificação/falsificação dos enunciados e de nossas pretensões cognitivas, conquanto essas explicações não sejam o propósito de Ser e Tempo. deixa Ser e Tempo com uma lacuna relevante.

Para além do caráter vago desse discurso sobre descobrir-encobrir, é possivel questionar. por outra perspectiva, a tese de Duits de que se pode explicar a verdade enunciativa por noções como a de desvelamento, descerramento e descoberta. Se, por um lado, é possível concordar

24 Do original: Insofar as the false proposition is immediately directed towards [...] its object, it is to be conceived in terms of an uncovering function. What marks it out from the true proposition is the fact that it dissimulates its object in its statement of it and in this sense is at the same time an en-covering, a concealing function. 
com Heidegger - e com Duits nesse ponto que o acontecimento de descerramento dos entes já deve ter se dado para que algo como a concordância de nossas pretensões cognitivas possa ser averiguado, por outro lado, há razões para acreditar que o que o conceito de verdade como desvelamento designa é algo anterior a qualquer complexidade enunciativa - aquilo que esse conceito denota é, a saber, o simples aparecer dos entes ou, no caso do velamento. o não aparecer dos entes ${ }^{25}$. Esse aspecto de simplicidade no desvelar-se dos entes é que estaria sendo nomeado, um aspecto o qual não se deixa confundir com a complexidade própria à verdade enunciativa. Um exemplo do acontecimento de verdade está na já mencionada verdade das sensações e simples apreensões, como o próprio Heidegger o afirma em $\S 44$ (b):

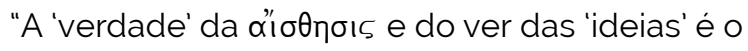
descobrir originário" (HEIDEGGER, 2001, p. 226). Também o descerramento, contudo, tal como Heidegger positivamente o caracteriza em Sere Tempo, teria o caráter de simplicidade. Em Taddei (2019, p. 290-291), destaco como, em passagens decisivas do $\S 32$, Heidegger caracteriza o descerramento como sendo simples, singelo (no original schlicht) e como isso aponta para um tipo específico de relação de fundação - como as simples apreensões estão fundadas no simples desvelamento do descerramento. Claro está que o descerramento é sempre descerramento de mundo e enquanto tal envolve sempre uma multiplicidade ôntica - assim, o descerramento é sob esse aspecto sempre complexo. Por essa razão mesma, a caracterização do descerramento como simples por Heidegger deve indicar que o importante no conceito de verdade como desvelamento é que os entes estejam desvelados em um descerramento fático e não como os entes se articulam nesse descerramento mesmo. Ora, o que importa fenomenologicamente para a verdade enunciativa é justamente como os entes são desvelados no modo do enunciado e no mostrar-se dos entes neles mesmos. Assim. qualquer referência ao jogo de velamento e desvelamento que a noção mais originária de verdade nomeia é insuficiente para elucidar a verdade enunciativa. Duits está certo ao dizer que o enunciado falso é ao mesmo tempo encobridor e descobridor - a questão é dizer como isso se dá, e o discurso vago sobre descobrir e encobrir em nada nos serve frente à herdada análise husserliana de meras intenções e intenções de preenchimento. Pode-se dizer, assim, que há uma assimetria entre a noção corrente de falsidade e a suposta noção mais originária de falsidade - de modo que Heidegger não explica por que, em primeiro lugar, algo como o simples velamento tem qualquer relação com a complexa incorreção enunciativa. O mero fato de a verdade enunciativa implicar um jogo de velamento e desvelamento - tese que não é negada por Tugendhat, e que é plenamente compativel com Husserl - não é resposta suficiente para essa questão. Assim, pode-se concluir que a segunda objeção de Duits contra Tugendhat também fracassa.

$\mathrm{Na}$ discussão conduzida até aqui, mostrei como duas tentativas de rejeitar a crítica tugendhatiana fracassam: Dahlstrom e Duits partem do pressuposto de que o ponto decisivo dessa crítica está na ausência de critérios para a distinção entre o verdadeiro e o falso e buscam mostrar como Heidegger de fato daria conta da falsidade em seu conceito mais originário de verdade. O fracasso dessas objeções se liga, principalmente, ao fato de não terem apreciado que a questão de fundo da crítica de Tugendhat é fundamentalmente essa: como justificar a passagem de um conceito corrente correspondentista de verdade para um conceito de verdade como desvelamento? Com que direito podemos chamar o descerramento o fenômeno mais originário de verdade? Em que medida não incorremos ai em mera equivocação? Na seção seguinte, pretendo argumentar em favor desse ponto, levantado pela primeira vez por Lafont (1994) e Smith (2007), considerando as objeções recentes de Wrathall (2011) contra esse modo

25 Nesse respeito, o argumento é o mesmo que se pode levantar contra a tese de Gethmann de que o conceito de verdade originário de Heidegger envolveria critérios de verdade pragmáticos. Cf. Taddei (2019). 
de interpretar a crítica de Tugendhat e a força dessa crítica mesma. Nesse contexto, pretendo mostrar duas vantagens dessa interpretação da critica de Tugendhat.

\section{A questão fundamental na crítica de Tugendhat}

Nas seções anteriores, propus que a crítica de Tugendhat é mais bem reconstruida como uma demanda de justificação da transição semântica de 'verdade'. Recentemente. Wrathall (2011, p. 34-39) expressou três espécies de reservas com relação a essa interpretação do ponto de vista sistemático, a demanda não seria válida;do ponto de vista da exegese do comentário crítico de Tugendhat, ela não seria, como o querem Lafont e Smith, a alegação/ acusação central de Tugendhat;do ponto de vista da exegese de Heidegger, ela não faria jus à própria compreensão heideggeriana do trabalho filosófico.Nessa seção, por razões de espaço, discutirei as reservas de segundo tipo e nas considerações finais farei alguns apontamentos relativos à terceira questão ${ }^{26}$.

Wrathall afirma en passant que o peso do texto de Tugendhat não estaria tanto na alegação de que o uso de 'verdade' para designar o desvelamento é indevido, mas muito mais na alegação de que Heidegger define ilegitimamente a verdade enunciativa como ser-descobridor simpliciter e que dai ele estende o conceito de verdade para o âmbito da descoberta (WRATHALL, 2011, p. 3536; o que em nosso esquema apareceu como as acusações (ii) e (iii)). Para Wrathall, a alegação de que Heidegger faz uso equivoco do termo 'verdade' ganha força justamente com as análises textuais do $\S 44$ (a). É porque Tugendhat teria mostrado que Heidegger não foi capaz de distinguir verdade e falsidade no âmbito enunciativo e no âmbito do desvelamento que a acusação do uso equívoco de 'verdade' ganha força.
Contra Wrathall, defendo que a relação entre as alegações é inversa: as acusações (ii) e (iii) - a perda de critérios para distinção do verdadeiro e do falso no âmbito da verdade enunciativa e da verdade como desvelamento - estão apoiadas na exigência resumida na acusação (vi) de nossa listagem terceira alegação na listagem de Wrathall: na exigência de uma transição semântica de um a outro conceito de verdade. Expressa de modo simples, minha proposta é a de que a acusação da perda da falsidade só é significativa supondo-se e Tugendhat assim o sabe - a questão da transição semântica como uma questão significativa. Mesmo a análise textual do $\S 44$ de Ser e Tempo nada pode realizar se não supusermos essa questão subjacente. Vejamos por quê.

Note-se, em primeiro lugar, que a mera acusação de que Heidegger não dá conta da falsidade no âmbito de sua verdade mais originária pode ser rebatida com a indicação de que Heidegger, como se mostrou ao longo desse artigo, em diversos momentos caracteriza esse conceito de verdade como não tendo um oposto, ou, ao menos, como não tendo um oposto no sentido em que a verdade enunciativa o tem. Se fosse o caso de que Tugendhat meramente alegasse que Heidegger não é capaz de dar conta de critérios de distinção de verdadeiro e do falso em seu conceito de desvelamento, poder-se-ia de maneira exitosa objetar que Heidegger de fato propõe um conceito de verdade desprovido desse tipo de normatividade. A perda de critérios só se torna uma questão à luz da exigência de uma elucidação da relação entre um e outro conceito de verdade e de como, ou se, uma transição é possivel.

Em segundo lugar, o fato de que a questão da transição esteja em jogo na acusação da perda de critérios se depreende do fato de que a análise se volta justamente para o momento em que Heidegger pretende operar a transição da verdade

26 Das outras objeções relevantes que Wrathall levanta contra a demanda para uma explicação da transição semântica de 'verdade' - um ponto que Wrathall discute sob a rubrica de "the rights argument" -, vale mencionar as seguintes: (i) essa demanda se apoia na premissa questionável de que as coisas ou bem têm ou bem não têm o direito de serem chamadas por uma palavra especifica (WRATHALL, 2011, p. 34); (ii) os defensores desse argumento jamais especificaram qual seria a normatividade exigida para a noção de desvelamento (WRATHALL, 2011, p. 35); (iii) Heidegger mesmo entende que o uso filosófico de termos não apenas não precisa fazer deferência ao uso ordinário, mas pode mesmo assumir o risco de fazer violência a esse uso (WRATHALL, 2011, p. 36). Ademais, Wrathall não interpreta a concessão de Heidegger a Tugendhat como tendo mais do que um significado pragmático (WRATHALL, 2011, p. 35). 
enunciativa para a verdade como desvelamento, no $\S 44$ (a). A acusação de Tugendhat não é, afinal, apenas a constatação de que o conceito de verdade como desvelamento não abre espaço para critérios de distinção entre verdadeiro e falso, mas sim de que Heidegger perdeu tais critérios perdeu com relação ao conceito enunciativo de verdade - uma perda especialmente constatável à luz da abordagem husserliana da verdade enunciativa que Heidegger cita.

Fala de modo mais decisivo, contudo, em favor dessa interpretação o fato de que Tugendhat emprega o termo Erweiterung - ampliação, extensão - para designar a passagem de um a outro conceito de verdade (TUGENDHAT, 1970 , p. 329, 345). É no mínimo curioso esse uso, uma vez que não há, em Ser e Tempo, registro de Heidegger assim caracterizar a passagem de um a outro conceito de verdade ${ }^{27}$. A nosso ver, esse uso reflete justamente uma tentativa de responder à questão a respeito da transição semântica de um a outro conceito de verdade - ampliação significa aí aumento do escopo do conceito a partir da eliminação de suas notas conceituais. A análise textual do § 44 (a) evidencia justamente que certas notas da definição de verdade são progressivamente cortadas - o que é interpretado por Tugendhat como condizente com uma ampliação da verdade de modalidades teóricas para o âmbito do descerramento enquanto tal.

Pode-se certamente questionar se Heidegger de fato opera em Ser e Tempo uma ampliação do conceito de verdade e se Tugendhat faz jus ao pensamento de Heidegger nesse quesito; não se pode questionar, contudo,que o emprego da noção de ampliação por Tugendhat depõe a favor da ideia de que o decisivo é não a ausência de critérios de distinção entre verdadeiro e falso quanto,mas sim, a perda desses critériosna transição semântica entre um e outro conceito de verdade. Essa é fundamentalmente a ótica segundo a qual Tugendhat encara a questão da verdade em Heidegger. Embora, por exemplo, seja também crítico da tradução do grego ó $\lambda \eta ́ \theta \varepsilon ı \propto$ por desvelamento, Tugendhat enfatiza claramente que: "A questão não é se $\alpha \lambda \eta j \theta \varepsilon ı \alpha$ foi entendida como desvelamento, mas sim, se ela foi assim entendida, o que desvelamento significaria" (TUGENDHAT, 1970, p. 261)28. Assim. independentemente de qualquer decisão a respeito de como traduzir $\alpha^{\alpha} \lambda \eta^{\prime} \theta \varepsilon ı \alpha$, a questão para Tugendhat é o que desvelamento significa, sobretudo frente ao conceito mais corrente e aceito de verdade como correspondência ${ }^{29}$. A passagem abaixo é significativa nesse sentido:

Heidegger de modo algum apenas passa por cima do problema da verdade. no sentido de que ele o deixe de lado e em aberto. Para a relação de Heidegger com o problema da verdade é decisivo. muito mais, justamente o fato de que ele se agarra à palavra 'verdade' e lhe dá uma interpretação nos termos ambíguos 'descobrir' e 'desvelamento', a qual não mais contém de maneira explícita o sentido específico de verdade, mas que pode ainda reluzir esse sentido(TUGENDHAT, 1970, p. 336, tradução nossa).30

A questão fundamental da crítica de Tugendhat ao conceito de verdade de Heidegger diz respeito, assim, não à questão da falsidade. mas sim, como enfatizaram Lafont e Smith, à equivocação do termo 'verdade' e ao direito de uso do termo para designar o fenômeno do desvelamento. Está no cerne da crítica de Tugendhat esse uso do termo 'verdade' que, ao buscar designar o fenômeno do desvelamento, ainda deixar reluzir o sentido tradicional de verdade como correspondência. Nesse artigo,

\footnotetext{
27 Com efeito, no $\S 44$ (b), Heidegger usa o termo "erweitern", estender, para caracterizar uma tese que ele rejeita: "E porque Aristóteles

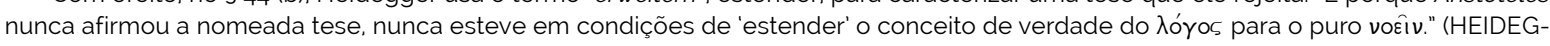
GER, 2001, p. 226, grifo do autor).

28 Cf. n. 1

29 É nesse contexto que se pode entender o que talvez seja o ponto de maior estranhamento, para intérpretes de Heidegger, na interpretação de Tugendhat - o fato de Tugendhat se referir em geral a conceitos de verdade, quando Heidegger raramente o faz. Trata-se de conceitos de verdade uma vez que se entenda por 'conceito' não representações subjetivas de qualquer natureza, mas meramente a fixação de um sentido do termo 'verdade' de modo a se averiguar a relação com outros sentidos de 'verdade'.

30 Do original: Heidegger geht also keineswegs über das Wahrheitsproblem einfach hinweg, in dem Sinn, daß er es nur beiseite und somit offen ließe. Für Heideggers Verhältnis zum Wahrheitsproblem ist vielmehr gerade entscheidend, daß er an das Wort "Wahrheit" festhält und ihm in den zweideutingen Worten „Entdecken" und „Unverborgenheit" eine Deutung gibt, die zwar den spezifischen Sinn von Wahrheit nicht mehr ausdrücklich enthält, aber doch noch in ihm schillern kann
} 
caracterizei essa questão, em consonância com a análise textual do $\S 44$ (a), como a questão da transição semântica de 'verdade' e nessa seção, pretendi ter mostrado que não faz violência ao texto de Tugendhat considerar essa questão como a questão central de sua crítica ao conceito de verdade de Heidegger.

\section{Considerações finais}

Restam ainda dois problemas em aberto no que se refere às reservas de Wrathall: se essa questão é, do ponto de vista sistemático, uma questão válida; e se essa questão se coaduna, do ponto de vista da exegese de Heidegger, com a compreensão heideggeriana do trabalho filosófico. Respostas para cada um dos dois problemas ultrapassam o escopo do presente artigo. À guisa de conclusão, contudo, vale mencionar o fato de que Heidegger faz, em $O$ fim da filosofia e a tarefa do pensamento, uma concessão concernente à questão da verdade no exato sentido do ponto que mostramos ser o fundamental de Tugendhat. Escreve Heidegger:

Pois já muito tarde levanta-se agora a questão: por que não mais se traduz aqui 'A $A$ rí $\theta \varepsilon ı \alpha$ pelo nome corrente, pela palavra 'verdade'? A resposta reza:

Na medida em que se compreende verdade no sentido "natural" da tradição como a concordância, validade no plano do ente, do conhecimento com o ente; mas também na medida em que verdade é interpretada a partir do ser como certeza do saber a respeito do ser, a 'A $A \eta^{\prime} \theta \varepsilon \varepsilon \alpha$, o desvelamento no sentido da clareira, não pode ser equiparada à verdade. Pelo contrário, a 'A $A n{ }^{\prime} \theta \varepsilon ı \alpha$, o desvelamento pensado como clareira, só então garante a possibilidade da verdade. [...]

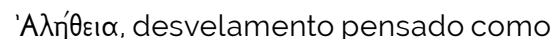
clareira da presença, ainda não é verdade. [...]

Em todo caso, uma coisa se torna clara: a questão da 'A $A \lambda^{\prime} \theta \varepsilon ı$, a questão do desvelamento como tal, não é a questão da verdade. Foi por isso inadequado [nichtsachgemäß] e, por conseguinte, enganoso [irreführend], denominar a 'A $A \eta^{\prime} \theta \varepsilon ı$, no sentido da clareira, de verdade (HEIDEGGER, 1988, p. 76-77 tradução nossa) ${ }^{31}$

Como é explícito, Heidegger nessa passagem afasta desvelamento e $\alpha^{\prime} \lambda \eta^{\prime} \theta \varepsilon ı \alpha$ de verdade. resguardando concordância, correção, para o sentido de 'verdade'. Não se trata de um mero acordo casual. Como atesta Zabala (2008, p. 127, n. 24), o primeiro registro público da crítica de Tugendhat é uma palestra no Seminário de Filosofia de Heidelberg em fevereiro de 1964palestra cujo conteúdo coincide com os parágrafos $\S 15$ e $\S 16$ do comentário Der Wahrheitsbegriff bei Husserl und Heidegger TUGENDHAT, 1970. p. VII) e é resumido posteriormente no artigo Heideggers Idee der Wahrheit (LAFONT, 1994, p. 154). ${ }^{32}$ A palestra de Heidegger O fim da filosofia e a tarefa do pensamento é proferida em abril de 1964, apenas dois meses após a palestra de Tugendhat. Certamente, a mera proximidade cronológica não é o que decide a favor da hipótese de que Heidegger esteja concedendo o ponto a Tugendhat ou se, ao contrário, ele estaria meramente fazendo uma "concessão pragmática" como entende Wrathall (2011, p. 36), isto é, sem maiores consequências teóricas. ${ }^{33} \mathrm{~A}$ proximidade cronológica, no máximo, sugere a plausibilidade da hipótese de uma concessão efetiva da parte de Heidegger. Para a confirmação

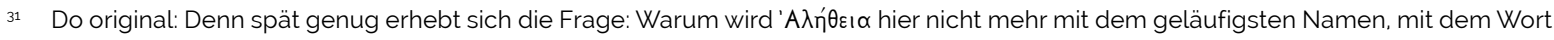
"Wahrheit", übersetzt? Die Antwort muss lautet:

Sofern man Wahrheit im überlieferten „natürlichen“ Sinn als die am Seienden ausgewiesene Übereinstimmung der Erkenntnis mit dem Seieden versteht, aber auch sofern die Wahrheit als die Gewißheit des Wissen vom Sein ausgelegt wird, darf die 'A $\lambda \eta^{\prime} \theta \varepsilon ı \alpha$ die Unverborgenheit im Sinne der Lichtung, nicht mit der Wahrheit gleichgesetzt werden. Vielmehr gewährt die 'A $\lambda \eta^{\prime} \theta \varepsilon ı \alpha$, die Unverborgenheit als Lichtung gedacht, erst die Möglichkeit von Wahrheit. [...]

'A $\lambda \hat{n} \theta \varepsilon ı$, Unverborgenheit als Lichtung von Anwesenheit gedacht, ist noch nicht Wahrheit. [...]

In jedem Fall wird das eine klar: Die Frage nach der 'A $\lambda \hat{r} \theta \varepsilon \_\alpha$, nach der Unverborgenheit als solcher, is nicht die Frage nach der Wahrheit.

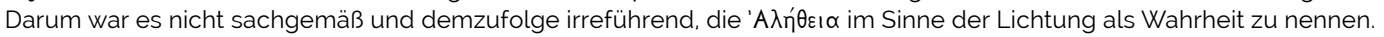

32 Cf. n. 4.

33 Como aponta Zabala (2008, p. 29). Apel teria sido o primeiro a atribuir a Heidegger uma concessão a Tugendhat. A isso, seguiu-se um debate envolvendo autores como Pöggeler, Gethmann, Habermas, além do próprio Apel, a respeito da correção dessa tese. Destaca-se como pouco convincente a posição de Pöggeler, para quem não há nenhuma concessão da parte de Heidegger, uma posição exitosamente rejeitada por Lafont (cf. 1994, p. 155). A posição de Zabala (2008, p. 30), semelhante à de Pöggeler, também é problemática por não fazer jus à letra do texto de Heidegger, quando esse afirma claramente ter feito uma opção enganosa (irreführrend). A argumentação de Wrathall nesse sentido é mais sofisticada, mas igualmente errônea - mostrar esse erro, contudo, não é parte desse artigo.
} 
dessa hipótese, a interpretação e análise dos textos em questão, bem como a reconstrução do pensamento de Heidegger são decisivas - o que não pode ser feito nessa conclusão senão que de modo alusivo. Fique, então, aludido aqui que a tese expressa na concessão de Heidegger não constitui uma passagem isolada: na própria O fim da filosofia e a tarefa do pensamento. Heidegger cita uma passagem de Ser e Tempo nesse sentido, ${ }^{34}$ posteriormente, a tese reaparece no Seminário sobre Heráclito com E. Fink e no Seminário de Zähringen. Na primeira aparição, o posicionamento de Heidegger é inequívoco:

$\alpha^{\prime} \lambda \eta^{\prime} \theta \varepsilon ı \alpha$ pensada como $\alpha^{\prime} \lambda \eta^{\prime} \theta \varepsilon ı$ a não tem nada a ver com "verdade", mas sim significa desvelamento [Unverborgenheit]. [...] A 'A $A \eta{ }^{\prime} \theta \varepsilon ı$ como desvelamento [Unverborgenheit] me ocupou sempre. ainda que a "verdade" tenha se interposto no meio do caminho (HEIDEGGER, 1970, GA 15, p. 260, tradução nossa). ${ }^{35}$

Não se pode, portanto, deixar de concordar com Lafont, quando afirma que a "situação [do debate em torno da critica de Tugendhat] ganha assim um efeito particular - e justamente irônico - na medida em que Heidegger mesmo foi um dos poucos que pareceu ter apreciado esse argumento (ou, conforme o caso, tomado em geral ciência desse argumento)" (LAFONT, 1994, p. 155). Se nesse trabalho, por um lado, mostramos que a demanda de uma elucidação da transição semântica de 'verdade' é condizente com o texto de Tugendhat, por outro lado, indicamos que Heidegger parece aceitar essa interpretação da crítica recebida. Assim, restam como tarefas futuras averiguar (i) se essa questão fundamental de Tugendhat é viável do ponto de vista sistemático como questão a respeito da transição de sentidos da linguagem por assim dizer natural para o emprego filosófico e (ii) se ela é tão incompatível com o pensamento de Heidegger como querem alguns intérpretes ou se há espaço, como as próprias passagens de
Heidegger acima citadas sugerem, para essa questão no âmbito de seu pensamento.

\section{Referências}

APEL, Karl-Otto. Transformação da Filosofia I: Filosofia Analítica, Semiótica e Hermenêutica. Trad. Paulo Astor Soethe. São Paulo: Loyola, 2000.

CROWELL, Steven G.Husserl, Heidegger, and Transcendental Philosophy: Another Look at the Encyclopaedia Britannica Article. In: CROWELL, Steven G.Husserl, Heidegger and the Space of Meaning: Paths Toward a Transcendental Philosophy. Evanston, IL: Northwestern University Press, 2001. p. 167-181.

DAHLSTROM, Daniel O. Heidegger's Concept of Truth. New York: Cambridge University Press, 2001.

DUITS, Rufus. On Tugendhat's Analysis of Heidegger's Concept of Truth. International Journal of Philosophical Studies v. 15, n. 2, june 2007, p. 207-223. https://doi.org/10.1080/09672550701383491

GETHMANN, Carl Friedrich. Dasein: Erkennen und Handeln: Heidegger im phänomenologischen Kontext. Berlin, de Gruyter, 1993. https://doi. org/10.1515/9783110882827

HEIDEGGER, Martin. O fim da filosofia e a tarefa do pensamento. Tradução: Ernildo Stein. São Paulo: Abril Cultural, 1983. p. 65-81. (Coleção Os Pensadores.)

HEIDEGGER, Martin. GA 15: Seminare. Frankfurt am Main: Vittorio Klostermann, 1986.

HEIDEGGER, Martin. Zur Sache des Denkens. Frankfurt am Main: Vittorio Klostermann, 1988.

HEIDEGGER, Martin. GA 21: Logik: die Frage nach der Wahrheit. Frankfurt am Main: Vittorio Klostermann, 1995.

HEIDEGGER, Martin. Sein und Zeit. 18. Aufl. Tübingen: Max-Niemayer Verlag, 2001.

HEIDEGGER, Martin. Ser e tempo. Tradução: Márcia Sá Cavalcante Schuback. 7. ed. Petrópolis, RJ: Vozes, 2012.

HEIDEGGER, Martin. Ser e tempo. Tradução: Fausto Castilho. Campinas, SP: Editora da Unicamp, 2014.

LAFONT, Cristina. Sprache und Welterschliessung: Zur linguistischen Wende der Hermeneutik Heideggers. Frankfurt ao Meno: Suhrkamp, 1994.

MOHANTY, Jitendra N. The Possibility of Transcendental Philosophy. Dordrecht: Martinus Nijhoff, 1985 https://doi.org/10.1007/978-94-009-5049-8

OVERGAARD, Søren. Heidegger's Concept of Truth Revisited. Sats - Nordic Journal of Philosophy, v. 3. n. 2 , 2002, p. 73-90. https://doi.org/10.1515/SATS.2002.73

\footnotetext{
34 Em Ser e Tempo, lê-se: "A tradução pela palavra 'verdade' e, sobretudo, as determinações conceituais teóricas dessa expressão escondem o sentido daquilo que os gregos enquanto compreensão pré-filosófica tinham como pressuposto 'autoevidente' do emprego terminológico de 'A $\lambda \hat{\prime} \theta \varepsilon ı \alpha$." (HEIDEGGER, 2001, p. 219).

35 Do original: ${ }_{\alpha}^{\prime} \lambda \eta^{\prime} \theta \varepsilon ı \alpha$ als $\dot{\alpha}^{\prime} \lambda \dot{n} \theta \varepsilon ı \alpha$ gedacht hat mit .Wahrheit" nichts zu tun, sondern bedeutet

Unverborgenheit. [...] Die $\alpha \lambda \eta^{\prime} \theta \varepsilon ı \alpha$ als Unverborgenheit hat mich immer schon beschäftigt, aber die „Wahrheit" schob sich dazwischen.
} 
RIBEIRO, André Antonio. Do desvelamento à clareira o desenvolvimento da noção de verdade em Heidegger. Controvérsia, v. 14, n. 2, 2018, p. 17-24.

SMITH, William. Why Tugendhat's Critique of Heidegger's Concept of Truth Remains a Critical Problem. Inquiry, v. 50, n. 2, 2007, p. 156-179. https://doi. org/10.1080/00201740701239749

Stroud, Barry. Transcendental Arguments. The Journal of Philosophy, v. 65, n. 9. 1968, p. 241-256. https:// doi.org/10.2307/2024395.

TADDEI, Paulo M. Da correspondência ao desvelamento: uma discussão da crítica de Tugendhat ao conceito de verdade de Heidegger. 2014. 130f. Tese (Doutorado em Filosofia) - Universidade Federal do Rio de Janeiro, Instituto de Filosofia e Ciências Sociais, Rio de Janeiro, 2014.

TADDEI, Paulo M. Uma restrição para interpretações pragmatistas de Ser e Tempo: uma avaliação da principal objeção de Gethmann à critica de Tugendhat ao conceito de verdade de Heidegger. Princípios: Revista de Filosofia (UFRN), v. 26, n. 50, p. 275-303, 30 maio 2019. https://doi.org/10.21680/ 1983-2109.2019v26n5olD16779

TUGENDHAT, Ernst. Der Wahrheitsbegriff bei Husserl und Heidegger. 2. ed. Berlin: Walter de Gruyter\& Co.,1970.

TUGENDHAT, Ernst. Heideggers Idee der Wahrheit. In: SKIRRBEKK, Gunnar. (ed.).Wahrheitstheorien: Eine Auswahl aus den Diskussionen über Wharheit im 20. Jahrhundert. Frankfurt: Suhrkamp,1993.

TUGENDHAT, Ernst. Selbstbewusstein und Selbstbestimmung. Frankfurt: Suhrkamp, 1979.

WRATHALL, Mark. Heidegger and Truth as Correspondence. In: Dreyfus, H. (org.). Heidegger Reexamined. York: Routledge, 2002. Vol. 2: Truth, Realism and the History of Being. New.

WRATHALL, Mark. Heidegger and Unconcealment: Truth, Language, and History. New York: Cambridge University Press, 2011.

ZABALA, Santiago. The Hermeneutic Nature of Analytic Philosophy. New York: Columbia University Press, 2008.

ZARADER, Marlène. Heidegger e as palavras de origem. Tradução do original "Heidegger et les paroles de l'origine": João Duarte. Lisboa, Instituto Piaget, 1990.

\section{Paulo Mendes Taddei}

Doutor em Filosofia pela Universidade Federal do Rio de Janeiro (UFRJ, Rio de Janeiro, RJ, Brasil), professor na Universidade Federal do Rio de Janeiro (UFRJ, Rio de Janeiro, RJ, Brasil).

\section{Endereço para correspondência}

Paulo Mendes Taddei

Universidade Federal do Rio de Janeiro

Instituto de Psicologia - Campus da Praia Vermelha

Av. Pasteur, 250, Fundos

Urca, 22290902

Rio de Janeiro, RJ, Brasil. 